\title{
SCIENTIFIC REPORTS

\section{OPEN Characterisation of mexiletine's translational therapeutic index for suppression of ischaemia-induced ventricular fibrillation in the rat isolated heart}

Louise M. Hesketh, Catherine D. E. Wilder, Niraja N. Ranadive, Georgia Lytra, Patrisia Qazimi, Jade S. Munro, Nakita Ahdi \& Michael J. Curtis ${ }^{\bowtie}$

The 'translational therapeutic index' (TTI) is a drug's ratio of nonclinical threshold dose (or concentration) for significant benefit versus threshold for adversity. In early nonclinical research, discovery and safety studies are normally undertaken separately. Our aim was to evaluate a novel integrated approach for generating a TTI for drugs intended for prevention of ischaemia-induced ventricular fibrillation (VF). We templated the current best available class $1 \mathrm{~b}$ antiarrhythmic, mexiletine, using the rat Langendorff preparation. Mexiletine's beneficial effects on the incidence of $V F$ caused by $120 \mathrm{~min}$ regional ischaemia were contrasted with its concurrent adverse effects (on several variables) in the same hearts, to generate a TTI. Mexiletine 0.1 and $0.5 \mu \mathrm{M}$ had no adverse effects, but did not reduce VF incidence. Mexiletine $1 \mu \mathrm{M}$ reduced $\mathrm{VF}$ incidence to $0 \%$ but had adverse effects on atrioventricular conduction and ventricular repolarization. Separate studies undertaken using an intraventricular balloon revealed no detrimental effects of mexiletine $(1$ and $5 \mu \mathrm{M})$ on mechanical function, or any benefit against reperfusion-related dysfunction. Mexiletine's TTI was found to be less than two, which accords with its clinical therapeutic index. Although non-cardiac adversity, identifiable from additional in vivo studies, may reduce the TTI further, it cannot increase it. Our experimental approach represents a useful early-stage integrated risk/benefit method that, when TTI is found to be low, would eliminate unsuitable class $1 \mathrm{~b}$ drugs prior to next stage in vivo work, with mexiletine's TTI defining the gold standard that would need to be bettered.

Coronary heart disease and acute myocardial infarction (AMI) constitute the largest cause of death worldwide ${ }^{1}$ with sudden cardiac death (SCD) responsible for approximately $50 \%$ of lethality ${ }^{2,3}$. Most SCD is due to ischaemia-induced arrhythmias, particularly ventricular fibrillation (VF) and ventricular tachycardia ${ }^{4}$.

Currently available antiarrhythmic drugs have failed against $\mathrm{SCD}^{5}$. The reason for this is that the benefit afforded by those drugs found to suppress SCD is offset by adverse drug reactions (ADRs); in some trials, mortality was actually increased ${ }^{6-8}$ while in other trials attempts to minimise ADR risk by use of lower drug doses resulted in loss of effectiveness ${ }^{9,10}$.

Presently the class $1 \mathrm{~b}$ antiarrhythmic, mexiletine, and the non-selective class III drug, amiodarone ${ }^{11}$, are the only antiarrhythmics prescribed for SCD outside the hospital setting, but even these drugs are not considered sufficiently efficacious for use in the larger lower-risk populations ${ }^{5,12}$ leaving a huge and longstanding unmet therapeutic need ${ }^{4}$. Since amiodarone is an anomalous example of a class (III) that is otherwise discounted as a solution to SCD owing to proarrhythmia ${ }^{5,12}$, this leaves only class $1 \mathrm{~b}$ agents as an avenue for new drug development.

An essential part of the process of any new drug development is to mitigate against ADRs during the nonclinical phase. In view of this, we and others ${ }^{13}$ advocate better characterization of the 'translational therapeutic index' (TTI) in nonclinical models before first in human (FIH) studies are attempted. A TTI can be defined as the ratio 
between the highest concentration without ADRs and the lowest concentration obtaining meaningful benefit, with a value of $>30$ being deemed a minimum for most therapeutic scenarios ${ }^{14}$.

Our attempts to develop a new safer and more effective antiarrhythmic drug have recently focused on the testing of an ischaemia-selective class $1 \mathrm{~b}$ drug, with preliminary data showing promise ${ }^{15}$. However, in order to gauge the potential advantage of this or any other new drug, we first need to formally define the gold standard: the template TTI of the best available current drug.

Mexiletine is prescribed for use against life-threatening ventricular arrhythmias ${ }^{5,16}$ with antiarrhythmic benefit mediated by block of sodium currents within the ischaemic region and termination of re-entrant conduction ${ }^{17}$. In addition to its widely documented noncardiac $\mathrm{ADRs}^{18}$, mexiletine also has the capacity to adversely increase atrioventricular $(\mathrm{AV})$ conduction time ${ }^{19-24}$. It can also elicit an adverse negative inotropic effect in vitro ${ }^{25,26}$, in $v_{i v o^{27,28}}$, and in the clinical setting ${ }^{29,30}$, albeit negative inotropic effects are not dose limiting ${ }^{31-39}$.

Despite its limitations, mexiletine is the only orally-active class $1 \mathrm{~b}$ antiarrhythmic to have had widespread clinical exposure, so its TTI in a nonclinical disease model would provide the necessary template to allow comparison, and evaluation of the potential value, of any novel class $1 \mathrm{~b}$ agent, by setting the height of the bar that any new drug must reach in order for it to become a candidate for translation.

A TTI in nonclinical research can be hard to obtain and harder to interpret owing to the multiplicity of experiments and models that may be used to generate different types of data (e.g., concentration-dependence of channel block, receptor affinity, pharmacokinetic data, and dose-dependence of effectiveness in a disease model) constituting the nonclinical portfolio. However, these obstacles diminish if readout for benefit and adversity are obtained at the same time using a single preparation (contiguously). If, in addition, studies are undertaken in vitro or ex vivo, complications associated with steady state drug concentration (affected by drug metabolism and distribution and plasma protein binding) can be disregarded and the TTI can be defined in terms of drug concentration rather than dose $^{13}$.

Thus, in the present study we have characterized the TTI of mexiletine in the rat isolated heart, a standardized bioassay for detecting beneficial drug effects on ischaemia-induced $\mathrm{VF}^{40}$ and cardiac ADRs. The latter are manifest and defined as any effect on heart rate, coronary flow, intervals in the electrocardiogram (ECG), or ventricular mechanical function before the onset of, or during, ischaemia.

Using this integrated approach, we found that suppression of ischaemia-induced VF could not be obtained at any concentration devoid of one or more ADR. Given this, and the evidence that noncardiac ADRs are the threshold ADRs for mexiletine in vivo in humans ${ }^{31,34,35,37-39}$, it is evident that mexiletine has an unfeasibly narrow therapeutic window for suppression of ischaemia-induced VF $(\mathrm{TTI}<2)$. We propose that, in future research, one may use the present data set as a template with which to gauge the potential value of new drugs, using an equivalent protocol.

\section{Methods}

Arrive, ethical, legal and experimental requirements. Animal housing and husbandry were as previously described ${ }^{41}$ and in compliance with ARRIVE ${ }^{42}$, the UK Home Office Guide on the Operation of the Animals (Scientific Procedures) Act 1986, and appropriate guidance on experimental design and analysis ${ }^{43,44}$. All experiments were performed under project licence PPL 70/7491 at King's College London, and were approved by the King's College London Animal Welfare and Ethical Review Board.

Animals and general experimental methods and materials. Rats were chosen for studies because they have a coronary anatomy that lends itself to generation of reproducible susceptibility to ischaemia-induced VF that is well characterised, and the in vitro (Langendorff perfusion) variation lends itself to the tractable evaluation of the concentration-dependence of the effects of drugs on VF and other variables ${ }^{40}$. Male Wistar rats (254$475 \mathrm{~g})$ were anaesthetised with a lethal dose of sodium pentobarbitone $\left(170 \mathrm{mg} \cdot \mathrm{kg}^{-1}\right)$ and heparin $\left(160 \mathrm{IU} \cdot \mathrm{kg}^{-1}\right)$ via intraperitoneal (i.p.) injection to achieve a surgical level of anaesthesia, confirmed by removal of pedal and corneal reflexes. Hearts were then excised (causing death by exsanguination) and immediately submerged in cold $\left(4^{\circ} \mathrm{C}\right)$ Krebs solution containing $\mathrm{NaCl} 118.5 \mathrm{mM}, \mathrm{CaCl}_{2} 1.4 \mathrm{mM}$, glucose $11.1 \mathrm{mM}, \mathrm{NaHCO}_{3} 25.0 \mathrm{mM}, \mathrm{MgSO}_{4}$ $1.2 \mathrm{mM}, \mathrm{NaH}_{2} \mathrm{PO}_{4} 1.2 \mathrm{mM}$ and $\mathrm{KCl} 3 \mathrm{mM}$. Hearts were then cannulated via the aorta for Langendorff perfusion via the coronary arteries, and perfused with Krebs (as above), filtered ( $5 \mu \mathrm{m}$ pore size), warmed to $37^{\circ} \mathrm{C}$ and gassed with $95 \% \mathrm{O}_{2}$ and $5 \% \mathrm{CO}_{2}$ to achieve a $\mathrm{pH}$ of 7.4 , at a constant pressure of approximately $80 \mathrm{mmHg}$. Mexiletine (Sigma-Aldrich, UK) stock solutions were made up in a vehicle of 1:4, Ethanol (VWR International, UK): Water (PURELAB ELGA Process Water, UK). Krebs perfusate salts were purchased from VWR International, UK.

Coronary artery ligation. A unipolar electrode was inserted in the apex of the heart, connected to a PowerLab (ADInstruments, UK), and used to detect heart rate and rhythm, with arrhythmias defined, detected and analysed according to guidance from The Lambeth Conventions ${ }^{44}$. A silk suture (4-0) was sewn around the left anterior descending (LAD) coronary artery, 1-2 mm below the left atrial appendage towards the apex, and threading both ends of the suture through a polythene tube. The suture was later tightened with and clamped (using forceps) to occlude the LAD coronary artery, inducing regional ischaemia, and subsequently loosened to reperfuse the artery. Following completion of the experimental protocol, the involved zone (IZ) size, defined as the anatomical region of myocardium that had been subjected to ischaemia, was identified by re-occlusion during perfusion with 5\% disulphine blue dye (Patent blue VF sodium salt, Sigma-Aldrich, UK), dissected and quantified as $\%$ of total ventricular weight (TVW). An IZ size of $40-60 \%$ TVW was expected given the chosen suture positioning ${ }^{45}$.

Experimental design and protocol. Mexiletine concentrations were chosen to span values slightly below and above reported clinically effective free plasma concentrations for suppression of ventricular arrhythmias ${ }^{46,47}$. 
Three concentrations of were examined: $0.1 \mu \mathrm{M}, 0.5 \mu \mathrm{M}$ and $1 \mu \mathrm{M}$ ( $\mathrm{n}=18$ /group), all of which were compared with a matched vehicle control group $(3 \mathrm{x} \mathrm{n}=18)$. Initially, $1 \mu \mathrm{M}$ was examined in the expectation this would suppress VF but possess ADRs. Once this was confirmed, the lower concentrations of mexiletine were studied in order to reveal at what concentration VF suppression could be achieved without ADRs. This experimental design was implemented to minimise animal usage. All experiments were blinded and randomised and followed a defined protocol.

Following a 5 minute period of Krebs perfusion, measurements of heart rate (beats. $\mathrm{min}^{-1}$ ), coronary flow ( $\mathrm{ml}$. $\left.\min ^{-1} \cdot \mathrm{g}^{-1}\right), \mathrm{PR}$ interval and $\mathrm{QT}_{90}$ (QT interval at $90 \%$ repolarisation) interval times $(\mathrm{msec})$ were begun, repeated at specified time points during the protocol. Perfusate was then switched to a test solution or control. After a further 5 minutes, regional ischaemia was induced for 120 minutes, followed by reperfusion for 10 minutes, and then IZ size delineation. In a subset of the hearts perfused with $1 \mu \mathrm{M}$ mexiletine $(\mathrm{n}=9)$ a higher $\mathrm{K}^{+}$concentration of $5 \mathrm{mM} \mathrm{K}^{+}$was introduced at the $90^{\text {th }}$ minute of ischaemia, with mexiletine or control solution continued for the remainder of the protocol, to examine whether any antiarrhythmic or adverse effects of mexiletine were dependent on ambient $\mathrm{K}^{+}$in the heart, a factor examined previously and found to influence outcome in studies with other class I (and class IV) antiarrhythmics ${ }^{4-50}$. The 120 minute length of ischaemia was also chosen to capture beyond the scope of the full spectrum of phase 1 ischaemia-induced ventricular arrhythmias in the rat isolated heart, which arise and then dissipate during the first 90 minutes of regional ischaemia ${ }^{51,52}$. The occurrence of VF during the first 90 minutes of ischaemia was presented and analysed separately from VF occurring later because there is a possibility that mechanisms of VF differ between early and more sustained ischaemia, and the actions of drugs diminished, exacerbated or even converted from protective to proarrhythmic ${ }^{51,53}$. Our protocol was designed to explore all these possibilities without adding unnecessary extra groups (minimising animal usage).

Coronary flow and ECG analysis. Coronary flow $\left(\mathrm{ml} \cdot \mathrm{min}^{-1} \cdot \mathrm{g}^{-1}\right)$ was measured by timed collection of effluent, which was weighed $(1 \mathrm{~g}=1 \mathrm{ml})$, and then expressed relative to the TVW of the respective heart. ECG and pressure measures such as heart rate (beats. $\left.\mathrm{min}^{-1}\right), \mathrm{PR}$ and $\mathrm{QT}_{90}$ intervals $(\mathrm{msec})$, diastolic and developed pressures $(\mathrm{mmHg})$ were obtained only during sinus rhythm. Ventricular arrhythmias defined according to the Lambeth Conventions II ${ }^{44}$ were recorded as 'present' or 'absent' within sequential 30-minute time periods during ischaemia, and the during first 10 minute period of reperfusion.

Exclusion criteria. Any heart that, prior to switch to test solution, had a coronary flow that fell outside the range of 7 to $20 \mathrm{ml} \cdot \mathrm{min}^{-1}$. $\mathrm{g}^{-1}$, a sinus heart rate of less than 200 beats. $\mathrm{min}^{-1}$, or an IZ size less than $40 \%$ TVW was excluded from the study, and subsequently replaced to maintain equal group sizes while maintaining blinding ${ }^{41}$. Hearts that met exclusion criteria were not excluded if doing so would not affect the outcome of the study (i.e. if VF occurred despite the IZ being below the size criterion, which is used to ensure that if VF did not occur in an individual heart, it was not due to IZ being 'too small for VF to occur' ${ }^{54}$ ).

Supplementary studies assessing left ventricular contractile function. Evaluation of left ventricular function was undertaken using Krebs modified to contain $4 \mathrm{mM} \mathrm{KCl}$ in an experiment undertaken separately from the arrhythmia study, owing to technical reasons recently identified ${ }^{55}$. A deflated intraventricular balloon (IVB), made from complaint non-elastic material, attached to a pressure transducer was inserted into the left ventricle via the left atrium for assessment of two components of contractile function, namely diastolic function as defined by diastolic pressure, and inotropy as defined by developed pressure (the difference between peak systolic pressure and minimum diastolic pressure during a single cardiac cycle during sinus rhythm). Once attached to the perfusion apparatus, hearts were submerged in coronary effluent contained within a heated jacket $\left(37^{\circ} \mathrm{C}\right)$ to preclude a fall in temperature, later, during global ischaemia. The IVB was filled with a small volume of saline $(\sim 0.02 \mathrm{ml})$ so that a pressure could just be measured, and the arbitrary value on the syringe noted as the 'zero volume'. Using the zero volume as a reference point the syringe was then filled with a volume of saline (typically $\sim 0.12 \mathrm{ml}$ for a $0.7-0.9 \mathrm{~g}$ heart) sufficient to generate a developed pressure $>100 \mathrm{mmHg}$, without elevating diastolic pressure to $>10 \mathrm{mmHg}$ (avoiding excessive diastolic stretch). This volume was defined as the 'working volume' and was set when examining effects of solution switching and effects of ischaemia and reperfusion. After cessation of each protocol, the hearts were removed from the Langendorff set up, the atria and any extra-cardiac tissue was removed, and the TVW (g) was measured.

Experimental design and protocol. Mexiletine was evaluated at up to $5 \mu \mathrm{M}$ on the expectation based on clinical reports that adverse effects on contractile function would require a higher concentration than that evoking adverse effects on the $\mathrm{ECG}^{38}$. Each group was compared with a vehicle control group $(\mathrm{all} n=9)$. Following a 5 minute period of Krebs perfusion, measurements of heart rate (beats. $\left.\mathrm{min}^{-1}\right)$, coronary flow $\left(\mathrm{ml} \cdot \mathrm{min}^{-1} \cdot \mathrm{g}^{-1}\right)$, ventricular diastolic pressure $(\mathrm{mmHg})$ and developed pressure $(\mathrm{mmHg})$ were taken at various predetermined time points. A Starling curve was constructed by deflating the IVB to zero volume before inflating the IVB with $0.02 \mathrm{ml}$ increments of saline (up to a diastolic pressure $<20 \mathrm{mmHg}$ ) and recording the incremental changes in diastolic and developed pressure $(\mathrm{mmHg})$. Perfusate was then switched to one of the three test solutions and 5 minutes later a second Starling curve was constructed. Global ischaemia was then induced by clamping the tubing above the aortic cannula, maintained for 20 minutes. Reperfusion was initiated by releasing the clamp, using the same test solution, and maintained for 60 minutes, whence a third Starling curve was constructed to determine drug effects on recovery of mechanical function.

Data and statistical analysis. Selection of group sizes was based on previous experience with the models used $^{40}$, and an expectation that assessment of threshold concentrations achieving effects (i.e., detection of weak drug effects) would require larger group sizes than normal for establishing statistical significance, as found in 


\section{IZ Size (\%)}

A

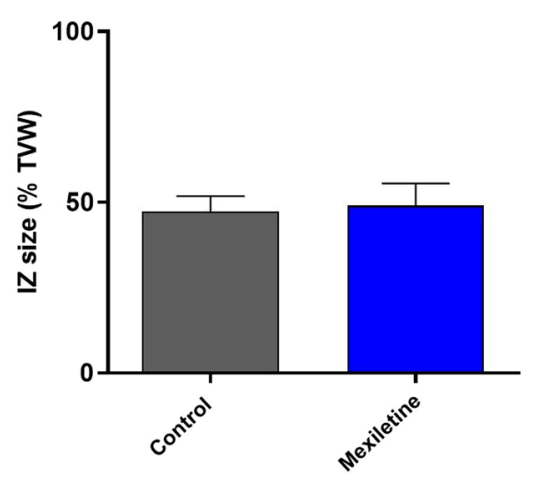

B

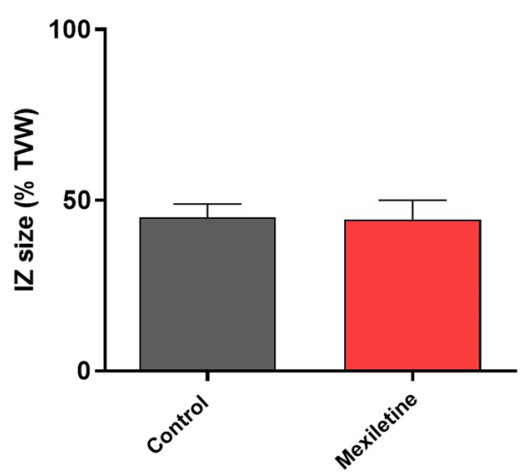

C

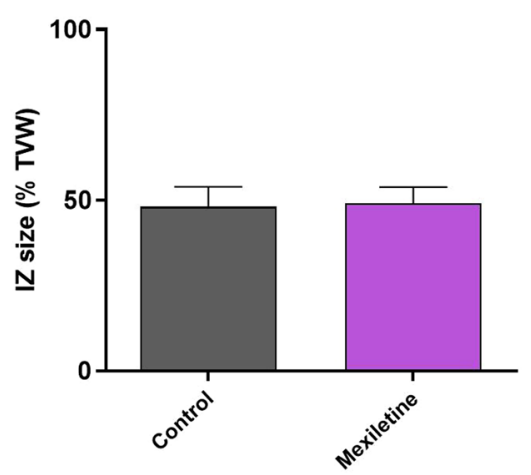

Figure 1. Involved Zone Size (\% TVW) resulting from proximal ligation of the left coronary artery in rat isolated hearts perfused with (A) $0.1 \mu \mathrm{M}$ mexiletine, (B) $0.5 \mu \mathrm{M}$ mexiletine and (C) $1 \mu \mathrm{M}$ mexiletine, measured as $\%$ total ventricular weight (TVW) each compared with separate groups of matched control hearts, $\mathrm{n}=18$ per group, mean \pm SEM. There were no statistically significant differences between groups.

previous studies ${ }^{41}$. Studies were undertaken using randomization followed by blinded analysis ${ }^{44}$ and in accordance with BJP's guidance in terms of group sizes, normalizations (none used) and Y axis labelling (all raw variables and no 'fold control') ${ }^{43}$. Statistical analysis was undertaken to determine whether individual test groups differed from drug-free controls. Gaussian distributed variables were subjected to an unpaired t test (when there were only two groups) or to ANOVA (1 way or 2 way, repeated measures when appropriate) when more than two groups were contrasted. After ANOVA, if F was significant and no variance inhomogeneity was detected, Dunnett's post hoc test was used to identify the groups in which variables had changed compared with controls. All Gaussian-distributed values were expressed as mean \pm SEM since representation of raw data values or standard deviations renders many data sets impossible to fathom due to clutter. Binomially distributed variables were compared using Fisher's exact tests. The threshold $\mathrm{P}$ value denoting statistical significance was $\mathrm{P}<0.05$. Differences between groups are described as effects or changes always and only when statistically significant. Statistical analysis was performed in GraphPad prism 7 (UK) software.

Ethical approval. All applicable international, national, and/or institutional guidelines for the care and use of animals were followed.

Declaration of transparency and scientific rigour. This paper adheres to the principles for transparent reporting and scientific rigour of nonclinical research recommended by funding agencies, publishers and other organisations involved with supporting this research.

\section{Results}

Design validation. IZ size was similar in each group (Fig. 1A-C), validating the effectiveness of randomisation in fulfilling the requirement for parity of arrhythmogenic stimulus ${ }^{54}$.

Concentration-dependence of effect of mexiletine on ischaemia-induced VF. The incidence of VF was approximately $50 \%$ in controls, providing scope for detection of inhibition by mexiletine (Fig. 2A-C). Mexiletine had no effect on VF at 0.1 and $0.5 \mu \mathrm{M}$ whereas $1 \mu \mathrm{M}$ abolished it, indicating a steep concentration-dependence (Fig. 2A-C). Representative ECG traces of sinus rhythm, ischaemia-induced VT and ischaemia-induced VF are displayed in Fig. 2D.

ADRs. Recorded variables in control hearts followed the pattern typical for the preparation ${ }^{51,55-57}$, with heart rate and coronary flow falling slightly during ischaemia, and then recovering during reperfusion, PR intervals varying little over time, and QT intervals increasing during ischaemia and decreasing during reperfusion (Fig. 3, 4 and $5 \mathrm{~A}-\mathrm{D}$ ). Neither 0.1 nor $0.5 \mu \mathrm{M}$ mexiletine had any effect on any variable (Fig. 3A-D). $1 \mu \mathrm{M}$ mexiletine did not affect coronary flow (Fig. 5B), or heart rate versus control (Fig. 5A), but it did prolong the PR interval and QT interval with effects beginning before the onset of ischaemia (Fig. 5C,D), indicating off-target pharmacology in non-ischaemic supraventricular and ventricular tissue. The introduction of $5 \mathrm{mMK}^{+}$at the 90 th minute of ischaemia did not alter these effects.

Effects of mexiletine on left ventricular contractile function. Mexiletine, tested only at the higher two concentrations ( $1 \mu \mathrm{M}$ and $5 \mu \mathrm{M}$ ), had no effect on heart rate or coronary flow (Fig. 6A,B), replicating findings (above) from hearts not fitted with an IVB. Prior to ischaemia, neither concentration of mexiletine affected diastolic or systolic pressure at the IVB's working volume (Fig. 6C,D). In all groups, diastolic pressure was increased, and developed pressure was decreased during $60 \mathrm{~min}$ reperfusion following global ischaemia with the partial recovery of function during reperfusion not altered by 1 or $5 \mu \mathrm{M}$ mexiletine (Fig. 6C,D). 


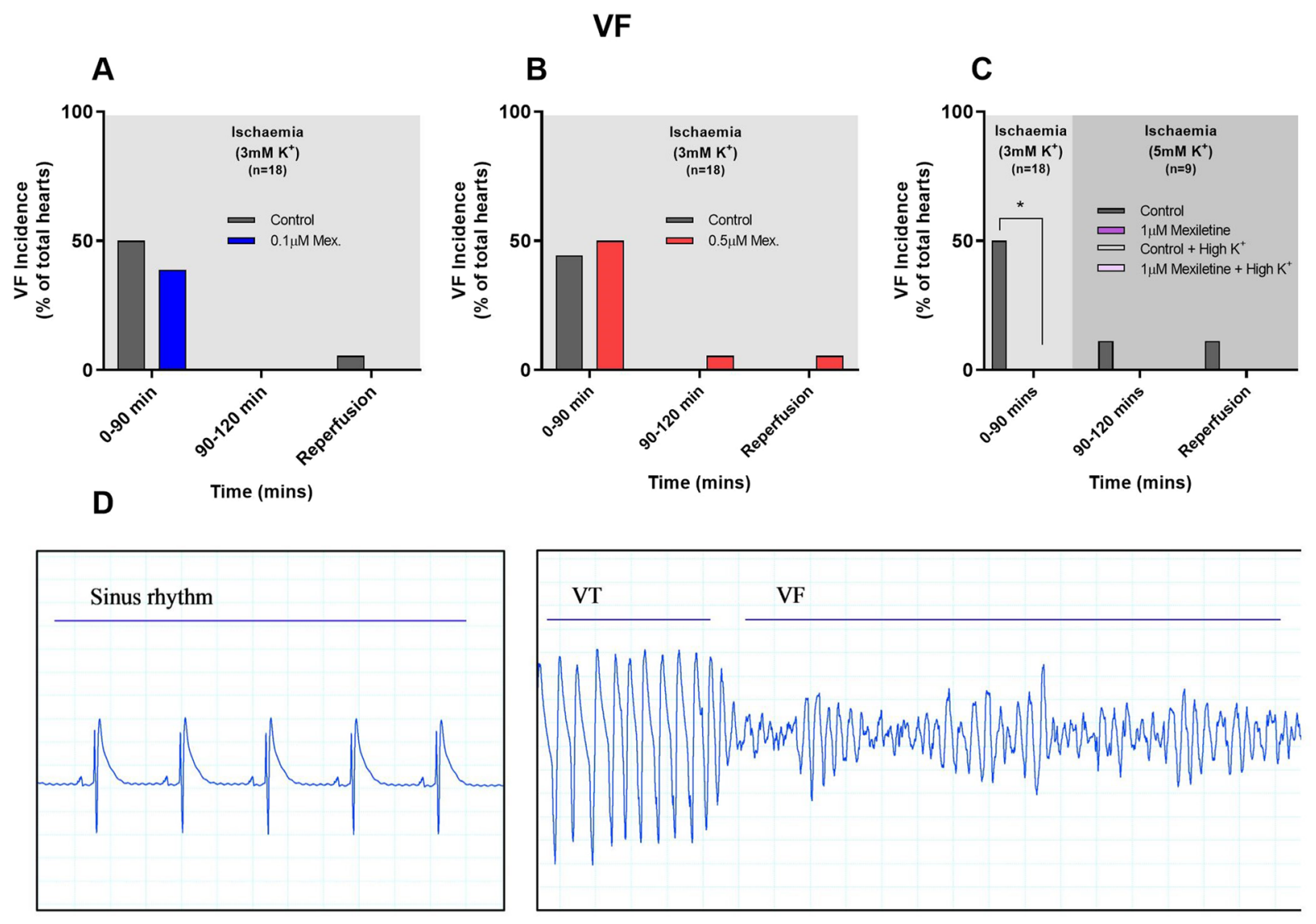

Figure 2. Incidence of Ventricular Fibrillation (\% of total hearts per group) during $120 \mathrm{~min}$ of regional ischaemia, and (separately) during $10 \mathrm{~min}$ reperfusion, for rat hearts perfused with or without (A) $0.1 \mu \mathrm{M}$ mexiletine, (B) $0.5 \mu \mathrm{M}$ mexiletine and (C) $1 \mu \mathrm{M}$ mexiletine (here, in half of the hearts, the $\mathrm{K}^{+}$in the solution was changed $30 \mathrm{~min}$ before the start of reperfusion to $5 \mathrm{mM}$ with all other constituents including drug concentration unchanged), $\mathrm{n}=18$ per group, and $\mathrm{n}=9$ (for the last $30 \mathrm{~min}$ of ischaemia and $10 \mathrm{~min}$ reperfusion). $* \mathrm{P}<0.05$ versus control. (D) Representative ECG traces displaying sinus rhythm, ischaemia-induced VT and ischaemiainduced VF during first 30 mins of regional ischaemia.

Consistent with these findings, Starling curve analysis revealed that neither $1 \mu \mathrm{M}$ nor $5 \mu \mathrm{M}$ mexiletine had any discernible effect on either systolic or diastolic function prior to ischaemia, or during reperfusion, with the slope of each volume:pressure line indistinguishable from control throughout the protocol (Fig. 7A-F).

\section{Discussion}

Mexiletine and the need for quantitative nonclinical therapeutic window data. Among the few drugs used to treat severe life-threatening ventricular arrhythmias during, or following, $\mathrm{AMI}^{5,58}$ mexiletine is the archetypal orally-active class $1 \mathrm{~b}$ antiarrhythmic ${ }^{11}$. It is the only clinically used antiarrhythmic for prevention of SCD that represents an archetype that may serve as a gold standard, since the only other drug for this indication, amiodarone, is anomalous within its nominal class ${ }^{5}$, and not an archetype that may serve as a focus for novel drug development. Clinically effective plasma mexiletine concentrations that provide antiarrhythmic benefit without treatment-terminating ADRs are reported to be $0.5-2.0 \mu \mathrm{g} / \mathrm{ml}^{46,47}$. To achieve this, an oral dose of $200-300 \mathrm{mg}$ every 8 hours is required [16]. However, the plasma concentration range of a drug encountered therapeutically is often wider than the therapeutic window ${ }^{13}$. The average plasma concentration of mexiletine causing ADRs is $0.88 \mu \mathrm{g} / \mathrm{ml}$, and the threshold concentration triggering treatment withdrawal is approximately $0.95 \mu \mathrm{g} / \mathrm{ml}^{38}$. The clinical therapeutic window is thus concerningly narrow. Unsurprisingly therefore, although initial clinical trials reported positive findings ${ }^{31-35,37,39,59}$ mexiletine has not emerged as a drug for primary prevention of $\mathrm{SCD}^{12}$; as with all antiarrhythmics its ADRs are perceived to outweigh benefit in this context ${ }^{5,16}$. Consequently, since this, the most useful drug has limited utility, there remains an important unmet clinical need for primary prevention.

In mexiletine's nonclinical development phase it would have been useful to have had a clear characterization of the doses and concentrations obtaining safe antiarrhythmic activity. Currently, for a drug to be viable for advancement to therapeutic evaluation in humans it must have a an adequate $\mathrm{TTI}^{13}$, and the drug with the best TTI would serve as a template with which to judge developing drugs. Unfortunately, although mexiletine was examined for antiarrhythmic activity in a variety of animal models in vitro ${ }^{60}$, ex vivo $o^{61,62}$ and in vivo ${ }^{27,63-66}$, no systematic attempt was made to determine its TTI. The aim of the present study was to rectify this, using the highly tractable rat Langendorff isolated perfused heart model and, in doing so, exemplify the model/approach and provide a mexiletine data set for use as a template with which to evaluate whether novel, as yet, untested drugs offer an advantage. 


\section{A}
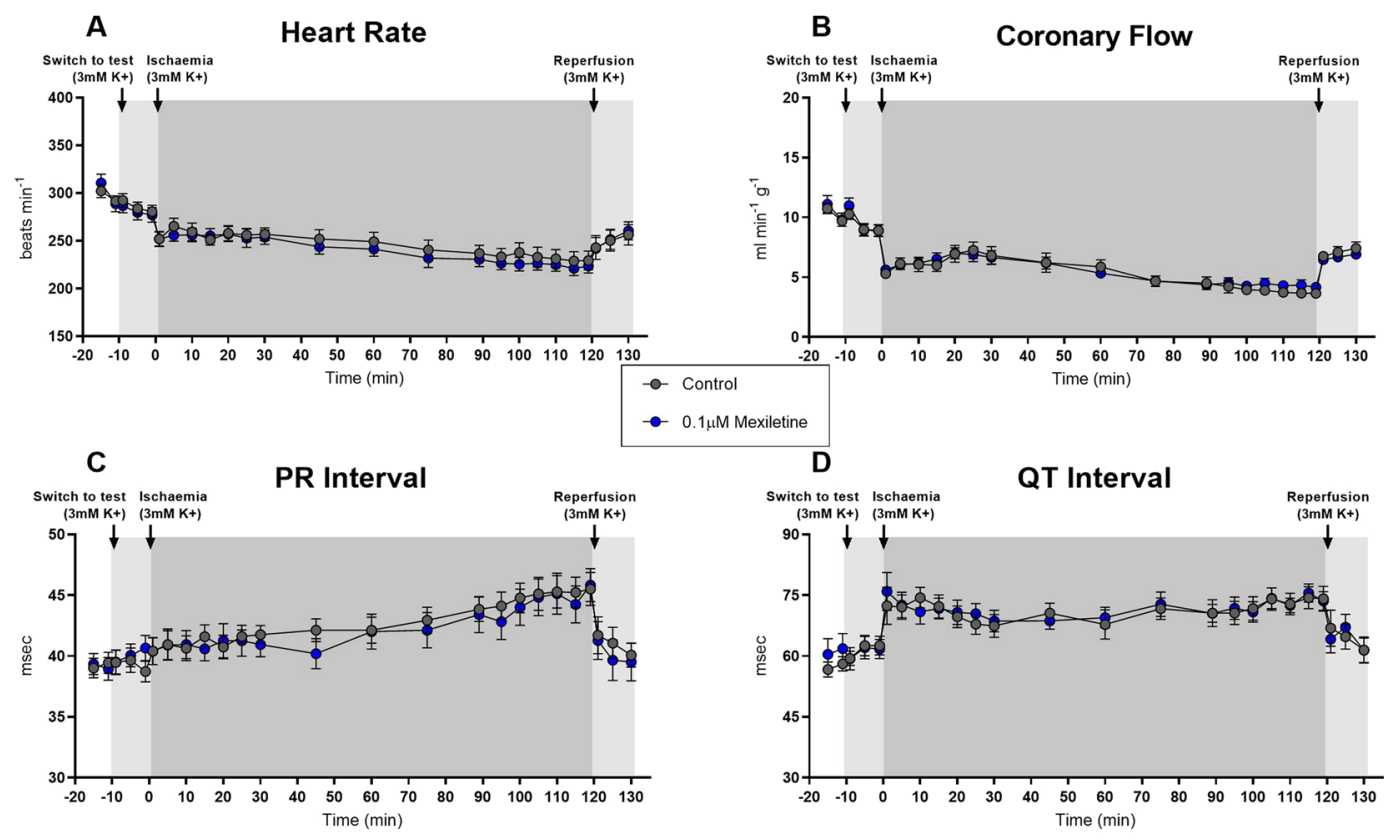

Switch to test Ischaem

D

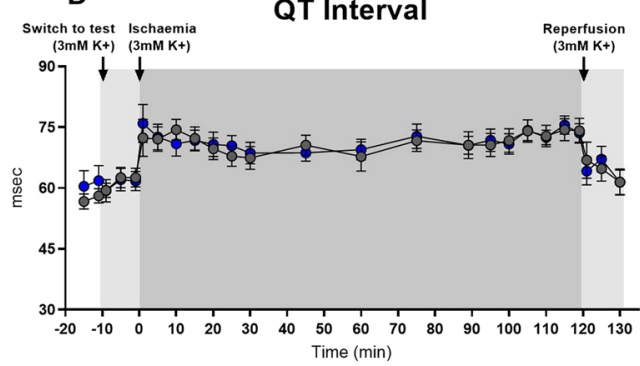

Figure 3. Haemodynamic and ECG changes in rat hearts perfused with or without $0.1 \mu \mathrm{M}$ mexiletine during 120 minutes left coronary artery ligation and 10 minutes reperfusion. (A) Heart rate (beats. $\mathrm{min}^{-1}$ ), (B) Coronary flow $\left(\mathrm{ml} \cdot \mathrm{min}^{-1} \cdot \mathrm{g}^{-1}\right),\left(\right.$ C) PR interval (msec), (D) $\mathrm{QT}_{90}$ interval (msec). $\mathrm{n}=18$ per group; mean \pm SEM. $* \mathrm{P}<0.05$ versus time-matched vehicle control. There were no statistically significant differences between groups for any variable.

A

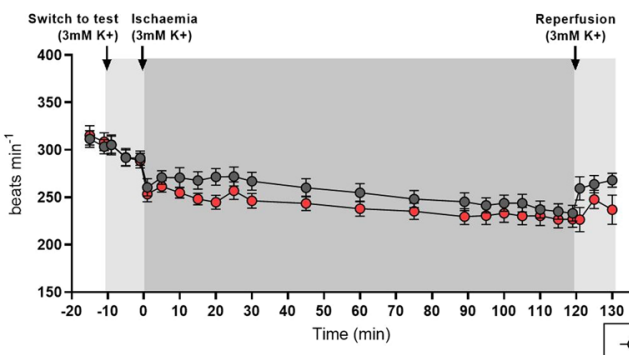

C

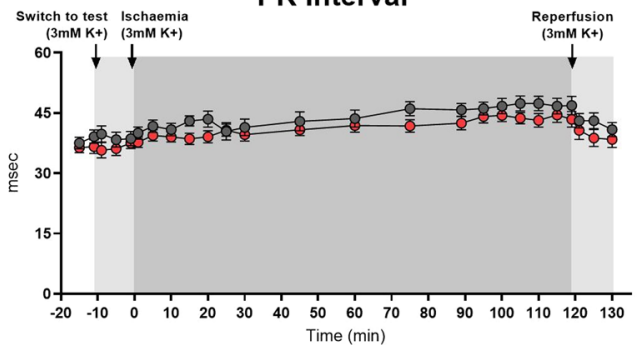

Coronary Flow

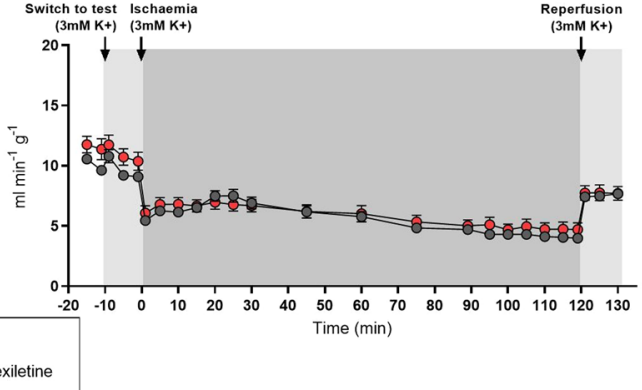

QT Interval

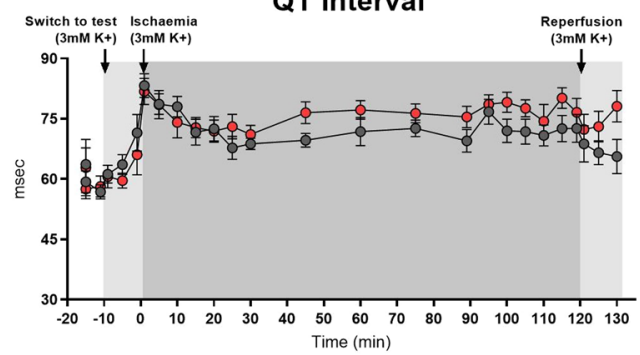

Figure 4. Haemodynamic and ECG changes in rat hearts perfused with or without $0.5 \mu \mathrm{M}$ mexiletine during $120 \mathrm{~min}$ left coronary artery ligation and $10 \mathrm{~min}$ reperfusion. (A) Heart rate (beats. $\left.\mathrm{min}^{-1}\right),($ B) Coronary flow (ml.min $\left.{ }^{-1} \cdot \mathrm{g}^{-1}\right),(\mathbf{C})$ PR Interval (msec), (D) $\mathrm{QT}_{90}$ Interval (msec). $\mathrm{n}=18$ per group, mean $\pm \mathrm{SEM} . * \mathrm{P}<0.05$ versus time-matched vehicle control. There were no statistically significant differences between groups for any variable.

Principal findings and implications. We found that $0.1 \mu \mathrm{M}$ and $0.5 \mu \mathrm{M}$ mexiletine did not exhibit antiarrhythmic effects. Unsurprisingly, these concentrations are lower than those (in plasma) reported to provide clinical effectiveness ${ }^{46,47}$. A doubling of concentration to $1 \mu \mathrm{M}$ was effective against VF. However this concentration precipitated ADRs, causing prolongation of the PR and QT intervals, just as a doubling of plasma concentration 


\section{A}
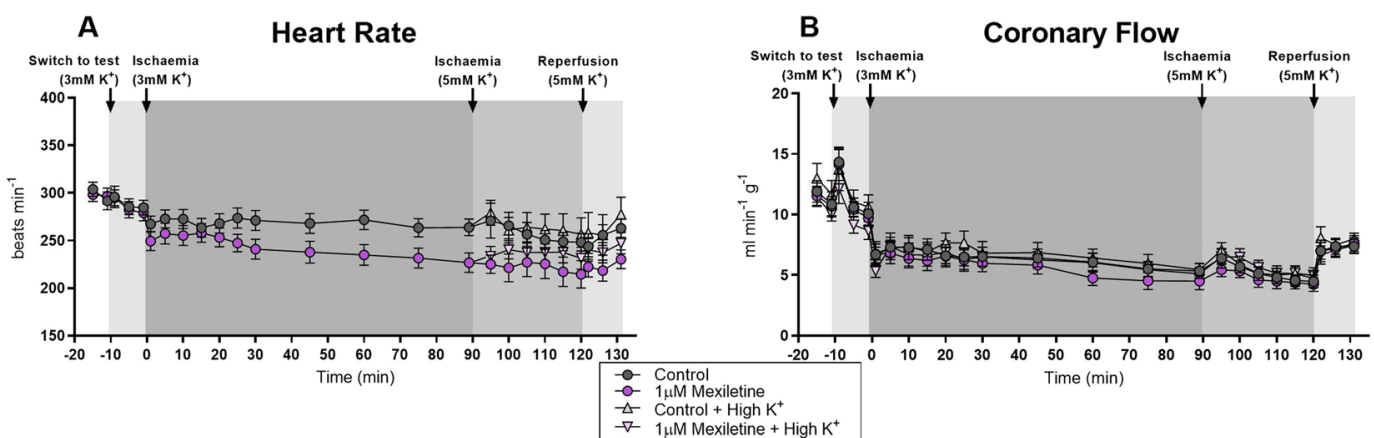

\section{C}
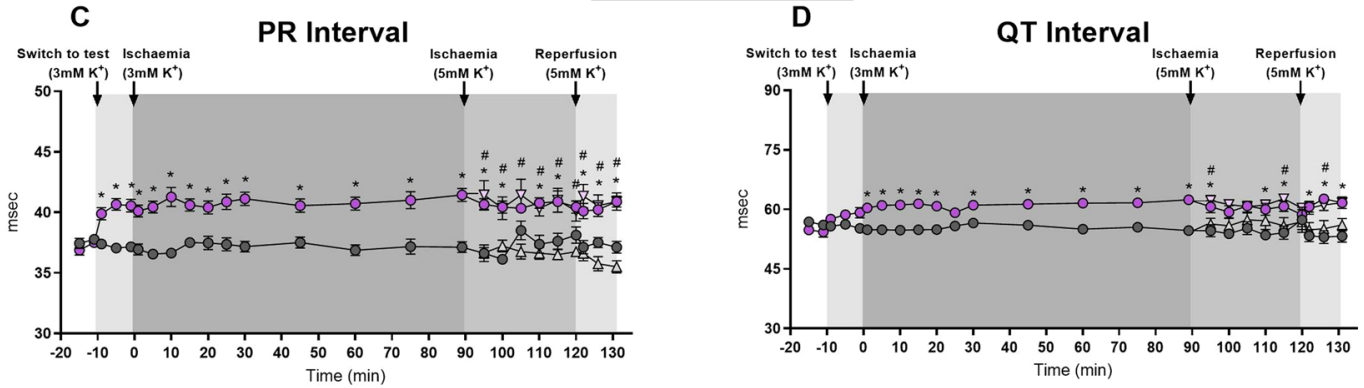

Figure 5. Haemodynamic and ECG changes in rat hearts perfused with or without $1 \mu \mathrm{M}$ mexiletine during 120 min left coronary artery ligation and 10 min reperfusion. Here, in half of the hearts, the $\mathrm{K}^{+}$in the solution was changed $30 \mathrm{~min}$ before the start of reperfusion to $5 \mathrm{mM}$ with all other constituents including drug concentration unchanged, $\mathrm{n}=18$ per group, and $\mathrm{n}=9$ for the last $30 \mathrm{~min}$ of ischaemia and 10 min reperfusion. (A) Heart rate (beats. $\mathrm{min}^{-1}$ ), (B) Coronary flow $\left(\mathrm{ml}_{\mathrm{min}}^{-1} \cdot \mathrm{g}^{-1}\right),\left(\right.$ C) PR Interval (msec), (D) QT $\mathrm{QT}_{90}$ Interval $(\mathrm{msec})$. Values are mean $\pm \mathrm{SEM}$. $* \mathrm{P}<0.05$ mexiletine versus time-matched vehicle control, ${ }^{*} \mathrm{P}<0.05$ mexiletine + high $\mathrm{K}^{+}$versus time-matched high $\mathrm{K}^{+}$vehicle control.
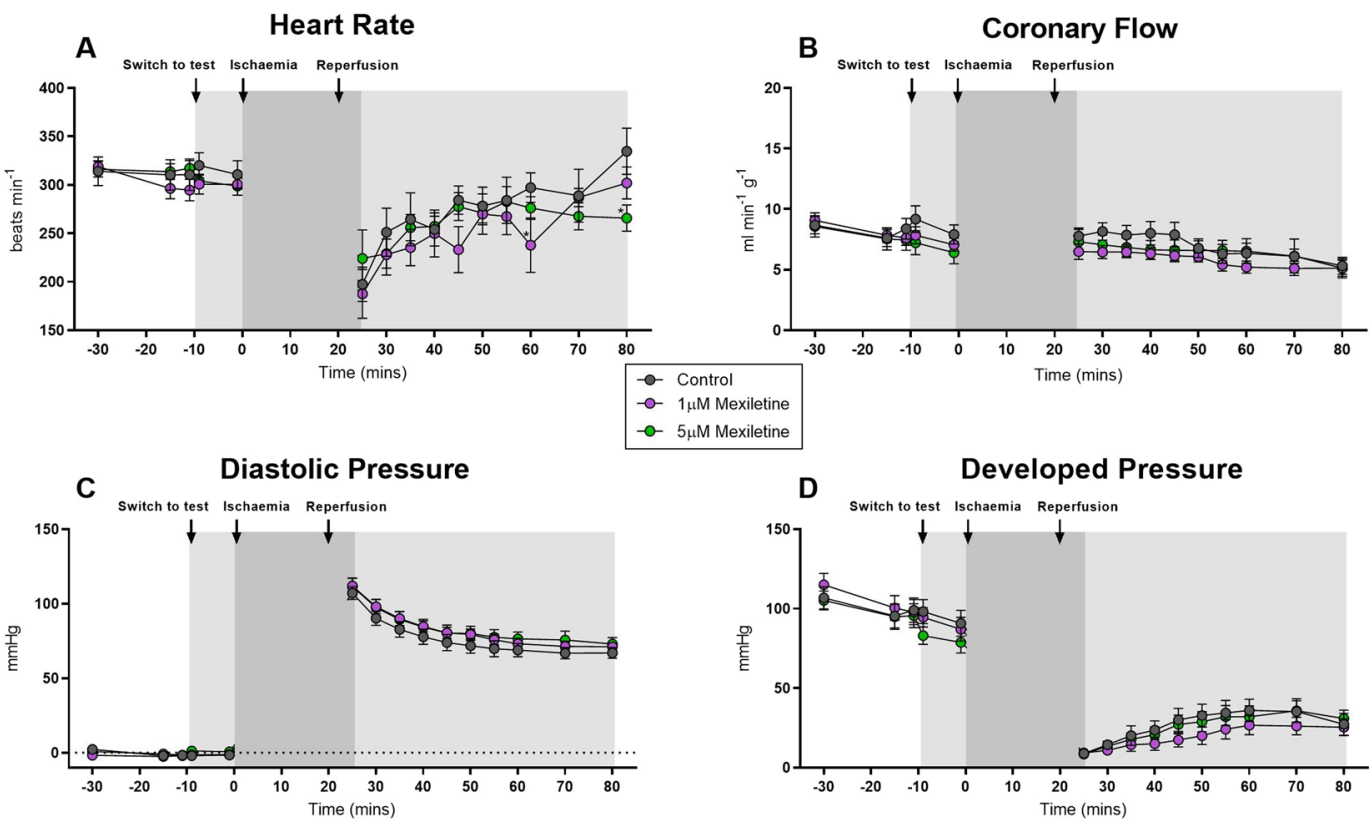

Figure 6. Haemodynamic and ECG changes during $20 \mathrm{~min}$ global ischaemia and $60 \mathrm{~min}$ reperfusion in rat hearts perfused with or without $1 \mu \mathrm{M}$ mexiletine or $5 \mu \mathrm{M}$ mexiletine. (A) Heart rate (beats. min $^{-1}$ ), (B) coronary flow $\left(\mathrm{ml} . \mathrm{min}^{-1} \cdot \mathrm{g}^{-1}\right),(\mathbf{C})$ diastolic pressure $(\mathrm{mmHg})$ and $(\mathbf{D})$ developed pressure $(\mathrm{mmHg})$. All $\mathrm{n}=9$ per group, mean $\pm \mathrm{SEM}$. $* \mathrm{P}<0.05$ versus time-matched vehicle control. There were no statistically significant differences between groups for any variable.

to $1 \mu \mathrm{g} / \mathrm{ml}$ results in serious ADRs in humans ${ }^{38}$, and subtherapeutic doses of mexiletine in a conscious rat model of ischaemia-induced VF caused an unacceptable reduction in blood pressure ${ }^{67}$. These results indicate that the consensus therapeutic index for mexiletine in humans (based on disparate data) was replicated by the TTI in 


\section{Diastolic Pressure}

A

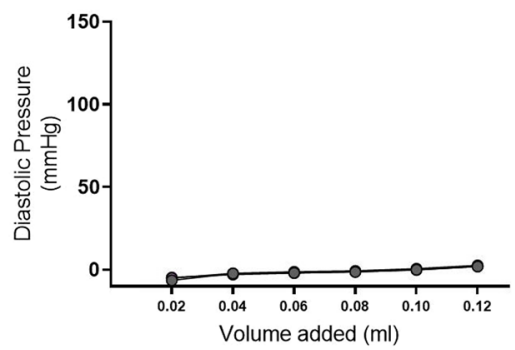

Developed Pressure

D

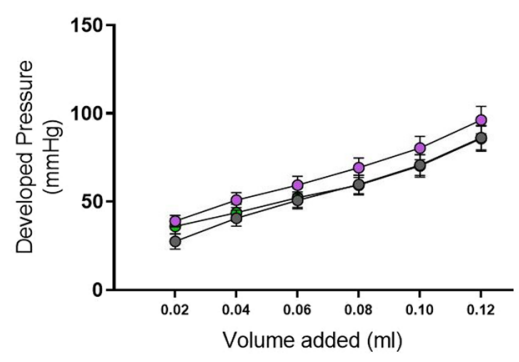

B
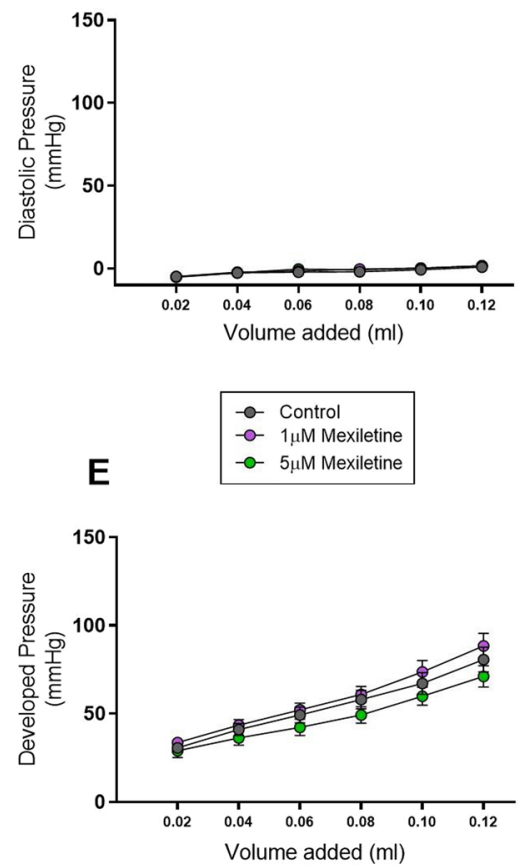

C

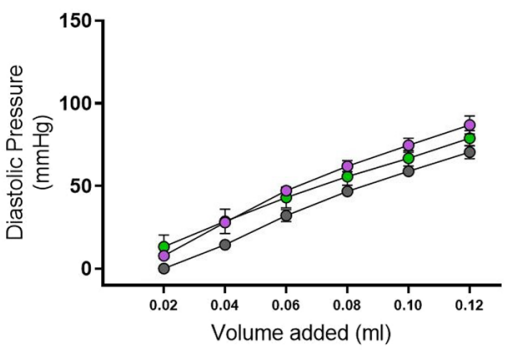

$\mathbf{F}$

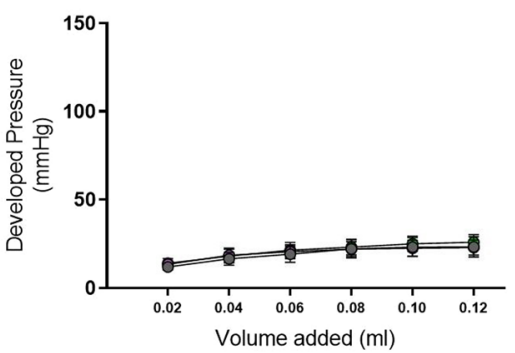

Figure 7. Changes in Diastolic pressure ( $\mathrm{mmHg}$ ) and Developed pressure ( $\mathrm{mmHg}$ ) generated from Starling curves in the rat Langendorff preparation, with or without $1 \mu \mathrm{M}$ mexiletine and $5 \mu \mathrm{M}$ mexiletine performed during Krebs perfusion (A,D), after switch to $1 \mu \mathrm{M}$ mexiletine, $5 \mu \mathrm{M}$ mexiletine or vehicle $(\mathbf{B}, \mathbf{E})$ and following $20 \mathrm{~min}$ global ischaemia and $60 \mathrm{~min}$ reperfusion $(\mathbf{C}, \mathbf{F})$. The slope of diastolic or developed pressure $(\mathrm{mmHg})$ and IVB volume $(\mathrm{ml})$ was analysed by linear regression analysis. All $\mathrm{n}=9$ per group, mean $\pm \mathrm{SEM}$. There were no statistically significant differences between groups for any variable.

the rat Langendorff preparation, and was confirmed to be impracticably small, requiring a concentration above $0.5 \mu \mathrm{M}$ yet below $1 \mu \mathrm{M}$ - a TTI of less than two. This is clearly insufficient to meet the 30 -fold criteria typically predictive of a safe, effective drug ${ }^{14}$.

Overall these findings validate the experimental approach elaborated in the present study and explain the limited clinical utility of mexiletine.

Study strengths and limitations. The Langendorff-perfused rat heart has been used extensively for evaluating drug-induced effects on ischaemia-induced VF, and is highly tractable ${ }^{40}$. Additionally, it provides scope for identifying drug-induced ADRs for numerous drug classes including those that block cardiac sodium current $\left(\mathrm{I}_{\mathrm{Na}}\right)$ and cardiac and vascular L-type calcium current $\left(\mathrm{I}_{\mathrm{CaL}}\right)^{40,49,50,53,57,68}$ albeit not delayed rectifying potassium current blockers $^{40}$. In addition to detection of ECG effects, increases in coronary flow in the perfused rat heart ${ }^{50,69}$ are predictive of peripheral vasodilatation and clinical hypotensive effects $\mathrm{s}^{70}$. The present approach therefore allows early identification of a new drug as unviable owing to dose limiting cardiac ADRs. However, an isolated perfused heart self-evidently cannot be used to assess noncardiac ADR risk.

Concern about possible noncardiac ADRs would arise if a drug were found to have a TTI in the rat isolated heart that is sufficiently large to justify further nonclinical development (i.e., >30), and noncardiac ADRs would then be examined by other means. The advantage of our approach, however, is that any drug with cardiac ADRs will have been excluded from further development. Thus, although mexiletine can cause central nervous system toxicity and gastrointestinal discomfort at plasma concentrations lower than those causing ADRs related to the ECG $^{31,34,35,37-39,71}$, its small TTI in the rat isolated heart renders its extracardiac ADRs irrelevant. For any new class 1 antiarrhythmic, a TTI of $>30$ would need to be met using our protocol, and only then would examination of its noncardiac ADRs be justified; reducing animal usage is an added benefit.

The rat heart has numerous advantages for TTI assessment of putative anti-VF drugs that are well documented, including an ability to manifest a reproducible susceptibility to ischaemia-induced $\mathrm{VF}^{40}$, but some hypothetical reasons for concern about this species choice remain. Class 1 drug-induced ventricular or AV nodal conduction abnormalities may occur to a greater extent, or at a lower drug concentration, in species such as the rat that has a basal heart rate higher than that of humans, if the drug's effects on $\mathrm{I}_{\mathrm{Na}}$ are characterized by slow binding and unbinding rates, typical of class $1 \mathrm{c}$ and $1 \mathrm{a}$ drugs ${ }^{72}$. However, this would not be a concern for drugs that bind and unbind from sodium channels quickly, such as mexiletine and other $1 \mathrm{~b}$ drugs $\mathrm{s}^{72}$. The present data accord with this since mexiletine's TTI in the rat heart mapped to the human therapeutic index. The predictive value of the rat heart may not be optimal for class 1c or 1a drugs, but these drugs are no longer used for treating 
ventricular arrhythmias, so the need to test a novel 1c or 1a drug in any nonclinical model of SCD and VF is unlikely to arise.

Conclusions. Nonclinical data sets can be complex with a variety of estimates of affinity and potency for actions on a range of different molecular targets and tissues. Additionally, safety and effectiveness are rarely investigated in tandem. This makes it difficult to obtain an estimate of a TTI. For a decision to be made on the likely clinical success and safety of a new antiarrhythmic, the nonclinical database must be sufficiently accurate to mitigate against false inference. In the SCD therapeutic area, failed translation has become the rule rather than the exception, with development blighted by low effectiveness coupled with ADRs at therapeutic dosage ${ }^{6-10}$. This requires better early-stage elaboration of the TTI using simple tractable approaches.

The integrated evaluation of safety and effectiveness (exemplified in the present study) aims to reduce animal requirements by effectively halving the number needed to estimate the TTI if effectiveness and safety were evaluated independently. The rat Langendorff preparation was shown to detect cardiac ADRs contiguously with beneficial effects on ischaemia-induced VF with a TTI $(<2)$ that replicates the consensus clinical therapeutic index. The experimental approach outlined was therefore validated and provides a template 'gold standard' for future early nonclinical assessment of novel antiarrhythmics, particularly antiarrhythmics with class $1 \mathrm{~b}$ characteristics, the one remaining class that is not intrinsically flawed owing to insurmountable ADRs including proarrhythmia related to its primary molecular pharmacology in the heart.

Finally, it is important to clarify the context of the present work. If a novel drug (class 1b, certainly, or drug of novel class), were to be found to have a promising therapeutic index in the rat Langendorff preparation this would allow its development to proceed, and if the drug were later found to have dose-limiting noncardiac adversity this will be detected by other means, for example when the efficacy and safety are examined using an in vivo animal model. Species with a lower basal heart rate than the rat, such as the $\operatorname{dog}^{73}$ are not suitable for early nonclinical evaluation owing to costs and ethical considerations. Our suggestion would be to utilise the Langendorff-perfused rat heart model to benchmark the TTI of a class $1 \mathrm{~b}$ agent and verify findings in vivo, and then in a second species, only if justified at each stage of experimentation (TTI $>30$-fold). Class $1 \mathrm{~b}$ drugs that do have dose-limiting cardiac ADRs that give rise to a narrow TTI will be detected in the rat Langendorff preparation, and rejected, saving the animals, time and cost that would have been expended exploring the drug's ADRs by other means.

Received: 19 December 2019; Accepted: 24 April 2020;

Published online: 21 May 2020

\section{References}

1. World Health Organisation. Global Health Estimates 2016: Deaths by Cause, Age, Sex, by Country and by Region, 2000-2016. (2018).

2. Myerburg, R. J. \& Junttila, M. J. Sudden Cardiac Death Caused by Coronary Heart Disease. Circulation 125, 1043-1052 (2012).

3. Wong, C. X. et al. Epidemiology of Sudden Cardiac Death: Global and Regional Perspectives. Hear. Lung Circ. 28, 6-14 (2019).

4. Huikuri, H., Castellanos, A. \& Myerburg, R. Sudden Death Due To Cardiac Arrhythmias. N. Engl. J. Med. 345, 1473-1482 (2002).

5. Dan, G. et al. Antiarrhythmic drugs-clinical use and clinical decision making: a consensus document from the European Heart Rhythm Association (EHRA) and European Society of Cardiology (ESC) Working Group on Cardiovascular Pharmacology, endorsed by the Heart Rhythm Soci. EP Eur. 20, 731-732an (2018).

6. Epstein, A. et al. Effect of Encainide and Flecainide on Mortality in a Randomised Trial of Arrhythmia Supression After Myocardial Infarction. N. Engl. J. Med. 321, 406-412 (1989).

7. Torp-Pedersen, C. et al. Dofetilide in patients with congestive heart failure and left ventricular dysfunction. N. Engl. J. Med. 341, 857-865 (1999).

8. Waldo, A. L. et al. Effect of d-sotalol on mortality in patients with left ventricular dysfunction after recent and remote myocardial infarction for the SWORD investigators. Lancet 348, 7-12 (1996).

9. The Multicenter Ditiazem Postinfarction Group. The effect of Diltiazem on mortality and reinfarction after myocardial infarction 1988. N. Engl. J. Med 319, 385-392 (1988).

10. The Danish Study Group on Verapamil in Myocardial Infarction. Effect of verapamil on mortality and major events after acute myocardial infarction (The Danish Verapamil Infarction Trial II - DAVIT II). Am. J. Cardiol. 66, 779-785 (1990).

11. Vaughan Williams, E. M. Classification of anti-arrhythmic drugs. In Symposium on cardiac Arrhythmias (eds. Sandøe, E., FlenstedJensen, E. \& Knud H, O.) 449-472 (Södertalje, Sweden, AB Astra, 1970).

12. Avanzini, F. et al. Antiarrhythmic Drug Prescription in Patients After Myocardial Infarction in the Last Decade. JAMA Intern. Med. 155, 1041-1045 (1995)

13. Muller, P. Y. \& Milton, M. N. The determination and interpretation of the therapeutic index in drug development. Nat. Rev. Drug Discov. 11, 751-761 (2012).

14. Redfern, W. et al. Relationships between preclinical cardiac electrophysiology, clinical QT interval prolongation and torsade de pointes for a broad range of drugs: evidence for a provisional safety margin in drug development. Cardiovasc. Res. 58, 32-45 (2003).

15. Hesketh, L. M. et al. Development of OCT2013, a hypoxia-activated prodrug of lidocaine, for the treatment of ischaemia-induced ventricular fibrillation. In Proceedings of the British Pharmacological Society 169P (2017).

16. Joint Formulary Committee. British National Formulary: Mexiletine Hydrochloride (online). BMJ Group and Pharmaceutical Press (2019).

17. Hondeghem, L. M. Antiarrhythmic agents: modulated receptor applications. Circulation 75, 514-520 (1987).

18. Monk, J. P. \& Brogden, R. N. Mexiletine: A Review of its Pharmacodynamic and Pharmacokinetic Properties, and Therapeutic Use in the Treatment of Arrhythmias. Drugs 40, 374-411 (1990).

19. Satoh, K., Narimatsu, A. \& Taira, N. Effects of antiarrhythmic drugs on AV nodal and intraventricular conduction as assessed in the isolated, blood-perfused AV node preparation of the dog. J. Cardiovasc. Pharmacol. 3, 753-768 (1981).

20. Harper, R. W., Bertil Olsson, S. \& Varnauskas, E. The effect of mexiletine on the electrophysical properties of the intact human heart. Scand. J. Clin. Lab. Invest. 37, 503-507 (2009).

21. Lang, K. F., Just, H. \& Limbourg, P. Studies on the effect of Melixetin (Kö 1173) on AV-conduction time and sinus pulse automation in persons with healthy hearts and in patients with disorders of the impulse-conduction system. Z. Kardiol. 64, 389-95 (1975).

22. Pozzoni, L. et al. Mexiletine action on the specialized tissues of the human heart. Int. J. Clin. Pharmacol. Res. 5, 229-36 (1985).

23. Roos, J. C., Paalman, A. C. \& Dunning, A. J. Electrophysiological effects of mexiletine in man. Br. Heart J 38, 1262-1271 (1976).

24. Touboul, P. et al. Electrophysiological study on mexiletine in man with reference to dose-response relation. Arch. Mal. Coeur Vaiss. 71, 1429-37 (1978). 
25. Honerjäger, $\mathrm{P}$. The contribution of Na channel block to the negative inotropic effect of antiarrhythmic drugs. In Controversial issues in cardiac pathophysiology 33-37 (Steinkopff, 1986).

26. Honerjager, P., Loibl, E., Steidl, I., Schiinsteiner, G. \& Ulm, K. Negative inotropic effects of tetrodotoxin and seven class 1 antiarrhythmic drugs in relation to sodium channel blockade. Naunyn-Schmiedeberg's Arch Pharmacol 332, 184-195 (1986).

27. Marshall, R. J., Muir, A. W. \& Winslow, E. Comparative antidysrhythmic and haemodynamic effects of orally or intravenously administered mexiletine and ORG 6001 in the anaesthetized rat. Br. J. Pharmac 74, 381-388 (1981).

28. Beltrame, J., Aylward, P. E., McRitchie, R. J. \& Chalmers, J. P. Comparative haemodynamic effects of lidocaine, mexiletine, and disopyramide. J. Cardiovasc. Pharmacol. 6, 483-90 (1984).

29. Gottlieb, S. S. \& Weinberg, M. Cardiodepressant effects of mexiletine in patients with severe left ventricular dysfunction. Eur. Heart J 13, 22-27 (1992).

30. Rousson, D., Piolat, C., Galleyrand, J., Ferry, S. \& Boissel, J. E. Systolic Time Intervals in Evaluation of the Negative Inotropic Effect After Single Oral Doses of Mexiletine and Disopyramide. Eur. J. Clin. Pharmacol. 30, 263-268 (1986).

31. Bell, J., Thomas, J., Isaacson, J., Snell, N. \& Holt, D. A trial of prophylactic mexiletine in home coronary care. Br. Heart J 48, 285-290 (1982).

32. Campbell, R. W. F. et al. Mexiletine in the prophylaxis of ventricular arrhythmias during acute myocardial infarction. J. Cardiovasc. Pharmacol. 1, 43-52 (1979).

33. Campbell, R. W. F. et al. Comparison of Procainamide and Mexiletine in prevention of ventricular arrhythmias after acute myocardial infarction. Lancet June, 10-13 (1975).

34. Chamberlain, D. A. et al. Oral Mexiletine in High-Risk Patients After Myocardial Infarction. Lancet 316, 1324-1327 (1980).

35. Breneman, G. et al. International Mexiletine and Placebo Antiarrhythmic Coronary Trial: I. Report on Arrhythmia and Other Findings. J. Am. Coll. Cardiol. 4, 1148-1163 (1984).

36. Kamiyama, T., Tanonaka, K., Harada, H., Nakai, K. \& Takeo, S. Mexiletine and lidocaine reduce post-ischemic functional and biochemical dysfunction of perfused hearts. Eur. J. Pharmacol. 272, 151-158 (1995).

37. Morganroth, J. Comparative Efficacy and Safety of Oral Mexiletine and Quinidine in Benign or Potentially lethal Ventricular Arrhythmias. Am. J. Cardiol. 60, 1276-1281 (1987).

38. Rutledge, J. C., Harris, F. \& Amsterdam, E. A. Clinical Evaluation of Oral Mexiletine Therapy in the Treatment of Ventricular Arrhythmias. J. Am. Coll. Cardiol. 6, 780-784 (1985).

39. Smyllie, H. C., Doar, J. W. H., Head, C. D. \& Leggett, R. J. E. A Trial of Intravenous and Oral Mexiletine in Acute Myocardial Infarction. Eur. J. Pharmacol. 26, 537-542 (1984).

40. Curtis, M. J. Characterisation, utilisation and clinical relevance of isolated perfused heart models of ischaemia-induced ventricular fibrillation. Cardiovasc. Res 39, 194-215 (1998).

41. Andrag, E. \& Curtis, M. J. Feasibility of targeting ischaemia-related ventricular arrhythmias by mimicry of endogenous protection by endocannabinoids. Br. J. Pharmacol. 169, 1840-1848 (2013).

42. Kilkenny, C., Browne, W. J., Cuthill, I. C., Emerson, M. \& Altman, D. G. Improving Bioscience Research Reporting: The ARRIVE Guidelines for Reporting. Animal Research. PLos Bio 8, 6-10 (2010).

43. Curtis, M. J. et al. Experimental design and analysis and their reporting: new guidance for publication in BJP. Br. J. Pharmacol. 172, 3461-3471 (2015).

44. Curtis, M. J. et al. The Lambeth Conventions (II): Guidelines for the study of animal and human ventricular and supraventricular arrhythmias. Pharmacol. Ther. 139, 213-248 (2013).

45. Ridley, P. D., Yacoub, H. \& Curtis, M. J. A modified model of global ischaemia: application to the study of syncytial mechanisms of arrhythmogenesis. Cardiovasc. Res. 26, 309-312 (1992).

46. Campbell, N. P., Kelly, J., Adgey, A. A. \& Shanks, R. The Clinical Pharmacology of Mexiletine. Br. J. Clin. Pharmacol. 6, 103-108 (1978).

47. Zipes, D. P. \& Troup, P. J. New Antiarrhythmic Agents. Am. J. Cardiol. 41, 1005-1024 (1978)

48. Curtis, M. J. \& Hearse, D. J. Ischaemia-induced and reperfusion-induced arrhythmias differ in their sensitivity to potassium: Implications for mechanisms of initiation and maintenance of ventricular fibrillation. J. Mol. Cell. Cardiol. 21, 21-40 (1989).

49. Farkas, A. \& Curtis, M. J. Limited Antifibrillatory Effectiveness of Clinically Relevant Concentrations of Class I Antiarrhythmics in Isolated Perfused Rat Hearts. J. Cardiovasc. Pharmacol. 39, 412-424 (2002).

50. Farkas, A., Qureshi, A. \& Curtis, M. J. Inadequate ischaemia-selectivity limits the antiarrhythmic efficacy of mibefradil during regional ischaemia and reperfusion in the rat isolated perfused heart. Br. J. Pharmacol 128, 41-50 (1999).

51. Clements-Jewery, H., Hearse, D. J. \& Curtis, M. J. Independent contribution of catecholamines to arrhythmogenesis during evolving infarction in the isolated rat heart. Br. J. Pharmacol 135, 807-815 (2002).

52. Ravingerova, T. Brief, intermediate and prolonged ischemia in the isolated crystalloid perfused rat heart: Relationship between susceptibility to arrhythmias and degree of ultrastructural injury. J. Mol. Cell. Cardiol. 27, 1937-1951 (1995).

53. Clements-Jewery, H., Kanaganayagam, G. S., Kabra, R. \& Curtis, M. J. Actions of flecainide on susceptibility to phase-2 ventricular arrhythmias during infarct evolution in rat isolated perfused hearts. Br. J. Pharmacol 147, 468-475 (2006).

54. Curtis, M. J. \& Hearse, D. J. Reperfusion-induced arrhythmias are critically dependent upon occluded zone size: Relevance to the mechanism of arrhythmogenesis. J. Mol. Cell. Cardiol. 21, 625-637 (1989).

55. Wilder, C. D. E. et al. Contractile function assessment by intraventricular balloon alters the ability of regional ischaemia to evoke ventricular fibrillation. Br. J. Pharmacol. 173, 39-52 (2016).

56. Dhanjal, T. S. et al. Trapped platelets activated in ischemia initiate ventricular fibrillation. Circ. Arrhythm. Electrophysiol 6, 995-1001 (2013).

57. Farkas, A. \& Curtis, M. J. Does QT widening in the Langendorff-perfused rat heart represent the effect of repolarization delay or conduction slowing? J Cardiovasc Pharmacol 42, 612-621 (2003).

58. Joint Formulary Committee. British National Formulary: Arrhythmias (online). BMJ Group and Pharmaceutical Press, https://doi. org/10.18578/BNF.590684308 (2019).

59. Halinen, M. O., Pentikainen, P. J., Helin, M. J. \& Rehnberg, S. Antiarrhythmic efficacy of combined intravenous and oral mexiletine in acute myocardial infarction. A double blind placebo-controlled study. Eur. Heart J 5, 675-683 (1984).

60. Yatani, A. \& Akaike, N. Blockage of the sodium current in isolated single cells from rat ventricle with mexiletine and disopyramide. J. Mol. Cell. Cardiol. 17, 467-476 (1985).

61. Almotrefi, A. \& Baker, J. The antifibrillatory potency of aprindine, mexiletine, tocainide and lignocaine compared on Langendorffperfused hearts of rabbits and guinea-pigs. J Pharm Pharmacol 32, 746-750 (1980).

62. Amerini, S. et al. Electrophysiological mechanisms for the antiarrhythmic action of mexiletine on digitalis-, reperfusion-and reoxygenation-induced arrhythmias. Br. J. Pharmac 86, 805-815 (1985).

63. Brooks, R. R., Miller, K. E., Carpenter, J. F. \& Jones, S. M. Broad Sensitivity of Rodent Arrhythmia Models to Class I, II, 111, and-IV Antiarrhythmic Agents. Exp. Biol. Med. 191, 201-209 (1989).

64. Komori, S. et al. Heart Effects of bidisomide (SC-40230), a new class I antiarrhythmic agent, on ventricular arrhythmias induced by coronary artery occlusion and reperfusion in anesthetized rats; comparison with mexiletine and disopyramide. Heart Vessels 10, 7-11 (1995). 
65. Komori, S., Sawanobori, T., Tamura, K., Kane, K. A. \& Parratt, J. R. Effects of NS-2, a New Class 1 Antiarrhythmic Agent, and AFD19, Its Active Metabolite, on Ventricular Arrhythmias Induced by Coronary Artery Occlusion and Reperfusion in Anesthetized Rats: Comparison with Disopyramide and Mexiletine. Jpn. J. Pharmacol. 65, 193-200 (1994).

66. Yoon, M. S. \& Han, J. Electrophysiologic effects of mexiletine on normal and ischemic ventricles. J. Electrocardiol. 15, 109-113 (1982).

67. Igwemezie, L. N., Beatch, G. N., McErlane, K. M. \& Walker, M. J. A. Mexiletine's antifibrillatory actions are limited by the occurrence of convulsions in conscious animals. Eur. J. Pharmacol. 210, 271-277 (1992).

68. Barrett, T. D., Hayes, E. S. \& Walker, M. J. A. Lack of selectivity for ventricular and ischaemic tissue limits the antiarrhythmic actions of lidocaine, quinidine and flecainide against ischaemia-induced arrhythmias. Eur. J. Pharmacol. 285, 229-238 (1995).

69. Thandroyen, F. T. Protective action of calcium channel antagonist agents against ventricular fibrillation in the isolated perfused rat heart. J. Mol. Cell. Cardiol. 14, 21-32 (1982).

70. Aoki, K., Sato, K., Kondo, S. \& Yamamoto, M. Hypotensive effects of Diltiazem to Normals and Essential Hypertensives. Eur. J. Clin. Pharmacol. 25, 475-480 (1983).

71. Chew, C. Y., Collect, J. \& Singh, B. N. Mexiletine: A Review of its Pharmacological Properties and Therapeutic Efficacy in Arrhythmias. Drugs 17, 161-181 (1979).

72. Hondeghem, L. M. \& Katzung, B. G. Antiarrhythmic agents - the modulated receptor mechanism of action of sodium and calcium channel-blocking drugs. Annu. Rev. Pharmacol. Toxicol. 24, 387-423 (1984).

73. Farmer, J. B. \& Levy, G. P. A Simple Method For Recording The Electrocardiogram And Heart Rate From Conscious Animals. Br. J. Pharmacol. Chemother. 32, 193-200 (1968).

\section{Acknowledgements}

This work was financially supported by the Medical Research Council. This study was funded by Medical Research Council (grant number: RDPL3MRCDMS).

\section{Author contributions}

L.M. Hesketh, N.N. Ranadive, G. Lytra, P. Qazimi, J.S. Munro and N. Ahdi performed the experiments. L.M. Hesketh, C.D.E. Wilder and M.J. Curtis designed the research study. L.M. Hesketh, C.D.E. Wilder, N.N. Ranadive, G. Lytra, P. Qazimi, J.S. Munro and N. Ahdi analysed the data. L.M. Hesketh and M.J. Curtis wrote the paper.

\section{Competing interests}

The authors declare no competing interests.

\section{Additional information}

Correspondence and requests for materials should be addressed to M.J.C.

Reprints and permissions information is available at www.nature.com/reprints.

Publisher's note Springer Nature remains neutral with regard to jurisdictional claims in published maps and institutional affiliations.

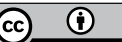

Open Access This article is licensed under a Creative Commons Attribution 4.0 International License, which permits use, sharing, adaptation, distribution and reproduction in any medium or format, as long as you give appropriate credit to the original author(s) and the source, provide a link to the Creative Commons license, and indicate if changes were made. The images or other third party material in this article are included in the article's Creative Commons license, unless indicated otherwise in a credit line to the material. If material is not included in the article's Creative Commons license and your intended use is not permitted by statutory regulation or exceeds the permitted use, you will need to obtain permission directly from the copyright holder. To view a copy of this license, visit http://creativecommons.org/licenses/by/4.0/.

(c) The Author(s) 2020 